\title{
WARISAN NILAI-NILAI GENDER DALAM SUKU BUGIS (PERAN KOMUNIKASI INTERPERSONAL DALAM KELUARGA )
}

\author{
Heritage Values of Gender in Buginese \\ (The Role of Interpersonal Communication in Family)
}

\author{
Mutia Nurul Fariza ${ }^{1}$, Muh. Nadjib ${ }^{2}$, Tuti Bahfiarti ${ }^{3}$ \\ ${ }^{1}$ Ilmu Komunikasi, Fakultas Ilmu Sosial dan Ilmu Politik, Universitas Hasanuddin, \\ (Email: thya_mwoh_deh@yahoo.com) \\ ${ }^{21}$ Ilmu Komunikasi, Fakultas Ilmu Sosial dan Ilmu Politik, Universitas Hasanuddin, \\ (Email nadjibnadjib@yahoo.com) \\ ${ }^{3}$ Ilmu Komunikasi, Fakultas Ilmu Sosial dan Ilmu Politik, Universitas Hasanuddin \\ (Email: tutibahfiarti@yahoo.com)
}

\begin{abstract}
ABSTRAK
Komunikasi yang terjalin antara orang tua dan anak merupakan salah satu cara dalam mewariskan nilai-nilai yang dapat menjadi dasar dalam pembentukan karakter anak. Penelitian ini bertujuan (1) untuk mengetahui proses komunikasi interpersonal antara orang tua dan anak dalam mewariskan nilai-nilai gender dalam budaya suku Bugis; (2) untuk mengetahui metode interaksi yang digunakan orang tua dalam mewariskan nilai-nilai gender kepada anak; (3) Untuk mengetahui faktor-faktor pendukung dan penghambat pewarisan nilai-nilai gender melalui komunikasi interpersonal dalam lingkungan keluarga. Metode penelitian yang digunakan adalah kualitatif deskriptif dengan pengumpulan data menggunakan teknik wawancara dan observasi. Analisis data dari penelitian ini menekankan kepada nilai-nilai gender yang terinternalisasi dari nilai-nilai lainnya, seperti nilai budaya, nilai pendidikan, nilai politik, nilai seni, nilai agama, dan nilai teknologi. Dari hasil penelitian menunjukkan bahwa proses komunikasi yang dilalui oleh keempat keluarga adalah sama. Melalui proses komunikasi anak mendapatkan pengetahuan tentang gender yang dijadikan pedoman dalam kehidupan. Metode yang digunakan oleh orang tua dalam mewariskan nilai-nilai gender berbeda-beda. Beberapa metode yang digunakan adalah pemberian nasehat, pemberian contoh, berdialog, penghargaan, dan pemberian hukuman. Kualitas komunikasi keempat keluarga sangat dipengaruhi oleh faktor pendukung dan penghambat.
\end{abstract}

Kata kunci: Komunikasi Interpersonal, Gender, Pola Asuh, Keluarga, Warisan Nilai-Nilai

\begin{abstract}
Communication between parents and children is one of ways to pass the values that can be the basic for children's development character. The study aims to investigate the process of interpersonal communication between parents and children to transfer the values of gender in Buginese culture; desribe the interaction method used by parents and depict inhibiting and the supporting factors of the passage of the value of gender through interpersonal communication in the family. The method used is qualitative descriptive and the data were collecting with dept-interview and direct observation. The analysis focuses on gender values internalized in the other values of culture, education, politics, artis, religion, and technology. The study indicates that the communication prosesses perfomed by the four families are identical. Through the process of communication, children gain knowledge about gender and use it as guide for their lives. The interaction method used by parents to pass the values of gender vary: advising; providing a role model; dialogues; rewarding; and giving a punisment. The communication quality of four families is highly influenced by the supporting and inhibiting factors.
\end{abstract}

Keywords: Interpersonal Communication, Gender, Parenting, Family, Heritage Values 


\section{PENDAHULUAN}

Keluarga memainkan peranan penting dalam melestarikan nilai-nilai kepada anak, salah satunya adalah nilai-nilai gender. Nilai gender merupakan suatu pedoman bagi lakilaki maupun perempuan dalam bertindak berdasarkan pada kesepakatan yang telah ditetapkan oleh lingkungannya (Perlas, 2006). Hal ini penting diwariskan dan diajarkan kepada anak sejak dini agar anak mendapatkan pengetahuan yang cukup untuk bekal dalam pembentukan karakternya nanti. Pengalaman anak sepanjang waktu bersama dengan orangorang yang dikenal di sekelilingnya dengan berbagai karakteristik dapat mempengaruhi perkembangan konsep dan kepribadian sosial mereka (Lestari, 2013). Disinilah peran orang tua sangat diperlukan dalam memberikan pemahaman nilai-nilai gender kepada anak.

Orang tua dituntut untuk memberikan perlakuan yang sama kepada anak laki-laki dan anak perempuan. Perbedaan perilaku antara anak perempuan dan laki-laki disebabkan adanya nilai-nilai gender yang diwariskan oleh orang tuanya. Perbedaan perilaku ini menjadi awal dari terbentuknya stereotaip gender (Fakih, 2013). Stereotip gender memberikan pelabelan secara umum kepada kaum laki-laki dan kaum perempuan. Kaum laki-laki diberi label maskulin, sedangkan kaum perempuan diberikan label feminim. Stereotaip seperti ini jelas menjadi penghalang anak untuk lebih mengekspresikan dirinya. Sehingga bagi siapapun yang tidak mengikuti pelabelan baku tersebut dianggap menyimpang atau tidak biasa (Mustadjar, 2013).

Pergeseran nilai inilah yang menjadi masalah utama dimana unit masyarakat yang terkecil yang hidup diperkotaan harus menghadapi masalah global ini. Keluarga dituntut untuk mengajarkan nilai-nilai budaya lokal kepada anak, sementara arus komunikasi dari luar sangat mempengaruhi pola asuh dan juga pembentukan karakter terhadap anak (Chrisler, 2011). Pentingnya peranan keluarga sebagai pewaris budaya, maka dari itu perlu dilakukan penelitian untuk mengungkap nilainilai budaya lokal yang masih diterapkan dalam keluarga modern (Wahidah, 2011).

\section{BAHAN DAN METODE Rancangan Penelitian}

Penelitian ini dilaksanakan di makassar pada april 2016-juli 2016 merupakan deskriptif kualitatif dengan teknik pengambilan data yang dilakukan melalui wawancara, observasi, dan dokumentasi. Informan ditentukan secara purporsive dengan kriteria-kriteria yang telah ditentukan. jumlah informan yang ditetapkan adalah lima keluarga Suku Bugis. Jumlah tersebut dipilih karena dianggap telah mewakili keluarga dari beberapa latar belakang.

\section{Informan penelitian}

Penelitian ini akan dilakukan dengan mengambil data di masyarakat yang ditentukan secara purposive dengan melihat dari beberapa karakteristik, sebagai berikut

Informan orang tua: 1)Keluarga Suku Bugis baik dari pihak ayah maupun pihak ibu. 2) Mempunyai anak laki-laki/perempuan berumur 6-11 tahun. 3) Orang tua (ayah dan ibu) serta anak tinggal secara bersama sebagai keluarga inti. 4) domisili makassar

Informan anak: 1) Anak lakilaki/perempuan berumur 7-11 tahun dari keluarga Suku Bugis baik dari pihak ayah maupun pihak ibunya. 2) Tinggal bersama orang tua (ayah dan ibu) sebagai keluarga inti. 3) domisili makassar

Sumber Data dan Teknik Pengumpulan Data

Teknik pengumpulan data didapatkan melalui data primer dan data sekunder. Data primer diperoleh dari hasil wawancara dan observasi. Data sekunder diperoleh dari studi pustaka dan pengumpulan literature yang berkaitan dengan penelitian ini. Metode penilitian awal adalah dengan menggunakan studi pustaka untuk melihat peniltianpenelitian sebelumnya dan mendapatkan informasi awal untuk persiapan penelitian selanjutnya. Selanjutnya digunakan metode wawancara untuk mendapatkan informasi dasar dari informan secara langsung. Metode ini akan memberikan gambaran awal mengenai informan yang akan diteliti selanjutnya. Informan yang bersangkutan adalah kepala keluarga, ibu rumah tangga, dan anak. Dan yang terakhir adalah metode pengamatan.

\section{Analisis Data}

Dengan menggunakan teknik analisis interaktif, ada beberapa tahapan yang perlu dilalui, yaitu: pengumpulan data (data collection), reduksi data (data condensation), penyajian data (data display), dan penarikan kesimpulan (conclusion). Penyajian data akan dianalisis secara deskriptif kualitatif. 
HASIL

\section{Profil Informan}

keluarga A, ayah merupakan lulusan S2 dan sekarang menjabat sebagai kepala sekolah, sedangkan ibunya merupakan lulusan S1 dan bekerja sebagai PNS di kantor agama. Keluarga ini memiliki 1 anak perempuan, dan 1 anak laki-laki. Anak pertama berusia 7 tahun dan telah bersekolah di SDIT. Sedangkan anak keduanya masih berusia 1 tahun.

Pada keluarga B, ayah dan ibu merupakan lulusan S1. Ayah saat ini bekerja sebagai polisi di daerah gowa sedangkan ibu bekerja sebagai pegawai honorer. Keluarga ini dikaruniai 2 orang anak perempuan. anak pertamanya telah berusia 8 tahun dan sekolah di SD Negeri yang berdekatan dengan kantor ibunya bekerja. Sedangkan yang bungsu masih berusia 3 tahun.

Pada keluarga $\mathrm{C}$, baik dari pihak ayah dan ibu merupakan lulusan S3 dan bekerja pada instansi yang sama. Bedanya ayah bekerja sebagai dosen sedangkan ibu bekerja sebagai staf peneliti. Keluarga ini dikaruniai dengan 2 anak laki-laki, dan 1 anak perempuan. semua anaknya disekolahkan pada sekolah yang sama di sebuah SDIT.

Dan keluarga B, ayah merupakan lulusan S1 sedangkan ibu merupakan lulusan SD. Ayah saat ini bekerja sebagai buruh kontraktor, sedangkan ibu bekerja sebagai IRT fulltime. Keluarga ini memiliki 3 orang anak laki-laki.

\section{Komunikasi Interpersonal Orang Tua dan Anak}

Komunikasi yang terjalin antara orang tua dan anak dapat menunjukkan kualitas hubungan keduanya. Beberapa elemen penting yang ada dalam komunikasi interpersonal dalam keluarga, adalah: pengirim, encoding, pesan, penerima, decoding, respon, dan feedback. Untuk memperjelas hal tersebut, dapat dilhat pada gambar (lampiran). Pada gambar ini terlihat bagaimana proses komunikasi yang berlangsung pada orang tua dan anak akan memberikan feedback pada anak berupa penerimaan/belum ada penerimaan pesan. Selain itu dapat dilihat bagaimana komunikasi itu bisa efektif dikarenakan oleh faktor-faktor pendukung, sedangkan dapat terjadi gangguan diakibatkan oleh beberapa faktor penghalang. Komunikasi dapat dikatakan efektif apabila penerima menginterpretasikan pesan yang diterimanya sebagaimana dimaksudkan oleh pengirim.

Selain daripada itu, komunikasi yang dibangun oleh orang tua dapat mempengaruhi pada pola perilaku yang akhirnya akan menjadi dasar pembentukan karakter anak. Anak akan merespon setiap pesan yang diterimanya dari orang tua. respon ini memiliki beragam reaksi tergantung bagaimana anak menerima dan memberikan makna pada pesan tersebut. Pesan-pesan yang disosialisasikan berkaitan dengan isu gender. Diterimanya pesan dengan baik sangat dipengaruhi oleh kualitas komunikasi orang tua itu sendiri. Penerimaan pesan yang baik oleh anak dapat dilihat segi kognitif, afektif, dan konatif. Hal ini tidak lepas dari kualitas komunikasi orang tua yang memberikan dampak besar kepada perkembangan dan pembentukan karakter anak. Ada orang tua yang sangat mengutamakan komunikasi dengan anak, ada juga orang tua yang terkesan tidak peduli akan hal tersebut. perilaku anak terbentuk akibat adanya pemberian makna yang dilakukan oleh anak dalam setiap interaksinya dengan orang tua. hal ini berarti bahwa ketika orang tua dan anak berinteraksi telah terjadi pemaknaan walaupun tidak semua pesan dapat dimakna secara utuh oleh anak. pemaknaan inilah yang menjadi dasar pada anak untuk memberikan respon berupa tindakan.

\section{PEMBAHASAN}

Pada penelitian ini, didapati bahwa proses komunikasi interpersonal orang tua dengan anak berjalan dengan lancar sehingga membentuk hubungan interpersonal yang dekat di dalam keluarga (Cangara, 2014). Hubungan interpersonal yang kuat terjadi diantara orang-orang yang mengisi kebutuhan emosional dan fisik satu sama lain (Liliweri, 2015:350). Hubungan itu pun dapat terjadi ketika keluarga dapat menjalin komunikasi yang baik. Berdasarkan pada teori CMM, komunikasi seseorang yang dilakukan secara kontinu akan membentuk episode-episode bersama yang dilalui oleh keduanya, sehingga semakin sering komunikasi dilakukan maka semakin banyak episode-episode yang dilalui dan membentuk hubungan yang semakin erat (Morissan,2013).

Dari 4 keluarga, ada tiga keluarga yang berkomunikasi secara efektif dengan anak sehingga sosialisasi nilai-nilai gender 
dapat berjalan sesuai dengan yang diinginkan oleh orang tua. Tetapi ada juga orang tua yang memandang bahwa nilai-nilai gender tidak perlu disosialisasikan karena anak akan mengetahui dengan sendirinya (Nugroho. 2008)

Proses komunikasi terjadi baik secara verbal, maupun non-verbal. Proses komunikasi yang dilakukan oleh orang tua kepada anak dalam penelitian dikatakan cukup efektif ketika adanya komunikasi yang terjalin terus menerus setiap harinya sehingga mampu membuat kebiasan-kebiasaan, dan akhirnya dapat diamati oleh anak yang selanjutnya akan ditiru (Griffin, 2005). Komunikasi dikatakan efektif ketika anak mampu untuk melakukan 'decoding' terhadap pesan yang diberikan oleh orang tua sebagai sender, sehingga akhirnya anak dapat memberikan respon dan feedback terhadap pesan yang disampaikan. Dalam proses komunikasi yang terjadi, anak mendapatkan banyak informasi mengenai bagaimana cara berperilaku sesuai dengan pemahaman gender oleh orang tuanya (Supraktiknya, 1995).

\section{KESIMPULAN DAN SARAN}

Berdasarkan hasil penelitian dan pembahasan mengenai warisan nilai-nilai gender dalam budaya bugis (studi kasus mengenai komunikasi interpersonal dalam keluarga) pada empat keluarga bugis yang bermukim di kota makassar adalah proses komunikasi yang terjalin antara orang tua dan anak menjadi hal penting dalam proses pewarisan nilai-nilai pada anak. anak belajar untuk memahami akan pesan-pesan komunikasi melalui interaksi dengan orang tuanya. dari orang tua yang bertindak sebagai komunikator, anak mendapatkan berbagai macam informasi termasuk mengenai tata cara berperilaku bagi anak laki-laki dan perempuan. feedback terhadap pesan-pesan komunikasi yang disampaikan dapat menjadi jawaban akan diterima/belumn diterimanya pesan tersebut. Hal ini dapat dilihat dari bagaimana cara anak berperilaku sehari-hari, cara berinteraksi dengan keluarga, kawan-kawan, dan orang yang baru dikenalnya, dan kemandiriannya. Selanjutnya juga dapat dilihat dari pemilihan warna dan permainan beserta dengan alasannya. Dari hal-hal tersebut dapat dianalisis sejauh mana pesan komunikasi yang berisi nilai-nilai gender dapat dipahami dan diterima oleh anak itu sendiri. Berdasarkan pada hasil kesimpulan, maka ada beberapa saran yang dapat dikemukakan:

1. Setiap keluarga harusnya memahami isu-isu gender untuk diwariskan pada anaknya. Hal ini penting untuk dipahami agar anak dapat terhindarkan pada masalah-masalah gender yang biasa terjadi di masyarakat luas, seperti streotipe gender, ketidaksetaraan gender. beberapa orang tua tidak mengambilberat terhadap masalah gender, sehingga anak tidak mendapatkan pemahaman gender seja usia dini. 


\section{DAFTAR PUSTAKA}

Cangara H. (2014). Pengantar Ilmu Komunikasi. Jakarta: Rajawali Pers.

Chrisler J.C. \& McCreary (2011). Handbook of Gender Research in Psychology. -

Fakih M. (2013). Analisis Gender dan Transformasi Sosial. Yogyakarta: Pustaka Pelajar.

Lestari S. (2013). Psikologi Keluarga: Penanaman Nilai Dan Penanganan Konflik Dalam Keluarga. Jakarta: Kencana.

Liliweri A. 2015. Komunikasi Antarpersonal. Kencana: Jakarta.

Griffin E. M. (2005). Communication: A first Look at Communication Theory. New York: McGraw Hil.

Morissan. (2013). Teori komunikasi: Individu hingga massa. Jakarta: Kencana.

Nugroho R. (2008). Gender dan strategi pengarus-utamaannya di Indonesia.: Yogyakarta.

Mustadjar M. (2013). Gender Dalam Keluarga Bugis (Studi Kasus Pada Lima Keluarga), Jurnal Kajian Perempuan "Bunga Wellu" Volume 7 No. 1 Juni 2010, Hal. 10-23

Wahidah N. (2011). Pola Komunikasi Dalam Keluarga. Musawa, Vol. 3, No. 2, Desember 2011: 163-178

Perlas C. (2006) Manusia Bugis. Grafika Mardi Yuana: Bogor

Supraktiknya. (1995) Komunikasi Antarpribadi: tinjauan psikologis. Yogyakarta: Penerbit Kanisius. 


\section{Lampiran :}

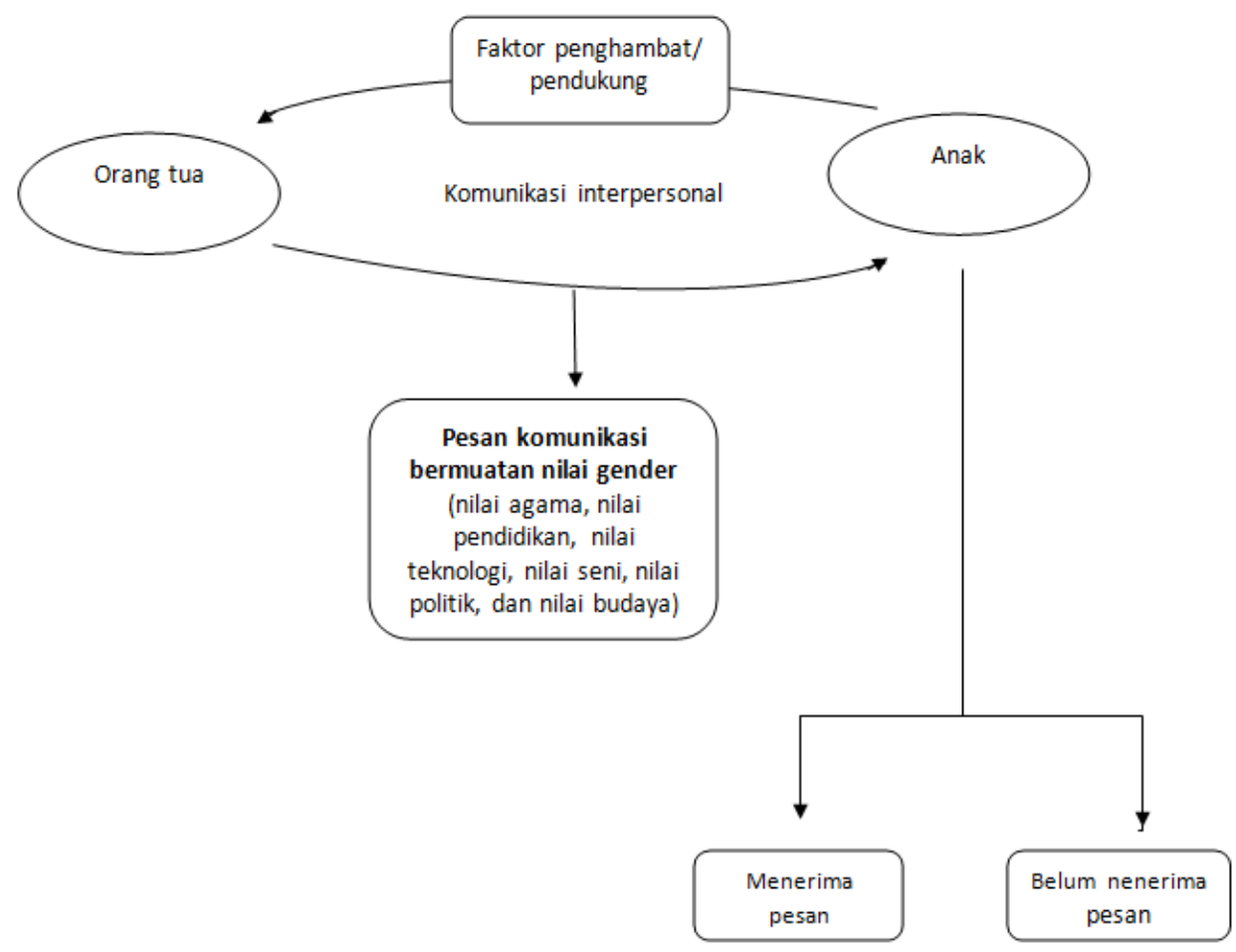

Gambar 1. Proses komunikasi interpersonal 